\title{
Características botânicas, importância socioeconômica e usos em saúde da castanha-do-Brasil (Bertholletia excelsa): Uma revisão
}

\section{Botanical characteristics, socioeconomic importance and health uses of Brazil nut (Bertholletia excelsa): A review}

\author{
Márcia de Jesus Amazonas da Silva ${ }^{1 *}$, Ariane Mendonça Kluczkovski ${ }^{2}$ Emerson SilvaLima ${ }^{3}$,
}

\section{RESUMO}

Bertholletia excelsa é uma espécie de florestas tropicais da família Lecythidacea. Fonte econômica primária para muitas populações extrativistas apresentando diversas características relevantes. Esta revisão tem como objetivo reunir artigos publicados nas bases de dados Periódico Capes, Pubmed, Science Direct e outros, utilizando descritores referentes a castanha do Brasil, sobre sua importância na saúde e economia. Foram encontrados 38387 artigos dos quais 107 foram avaliados subsequentemente com as leituras de título/resumos, destes 58 foram selecionados para nortear a revisão. Os resultados confirmam a importância do manejo econômico desta espécie nas comunidades tradicionais na cultura de coleta/beneficiamento, bem como suas propriedades biológicas as quais contribuem para a saúde da população. Estudos experimentais adicionais são necessários para a elucidação de mecanismos de ação, segurança e eficácia da espécie na tentativa do uso da planta como recurso biotecnológico.

Palavras-chave: Propriedades Biológicas; Plantas Medicinais; Economia; Anti-inflamatório; Antioxidante.

\section{ABSTRACT}

Bertholletia excelsa is a tropical rainforest species in the Lecythidacea family. Primary economic source for many extractive populations with several relevant characteristics. This review aims to gather articles published in the databases Periódico Capes, Pubmed, Science Direct and others, using descriptors referring to Brazil nuts, about their importance in health and economy. A total of 38387 articles were found, of which 107 were subsequently evaluated with the title/abstract readings, of which 58 were selected to guide the review. The results confirm the importance of economic management of this species in traditional communities in the culture of collection/processing, as well as its biological properties which contribute to the health of the population. More experimental studies are needed to elucidate mechanisms of action, safety and efficacy of the species in an attempt to use the plant as a biotechnological resource.

Keywords: Biological Properties; Medicinal Plants; Economy; Anti-inflammatory; Antioxidant.

\footnotetext{
1,2,3 Faculdade de Ciências Farmacêuticas, Universidade Federal do Amazonas
}

*E-mail: eslima@ufam.edu.br 


\section{INTRODUÇÃO}

As plantas medicinais representam um tratamento natural para várias doenças humanas, e uma rede potente de diversidade biológica com os compostos que as constituem. Possuem vantagens como baixo custo e subsistência independentes. No entanto, várias pesquisas necessitam ser realizadas para comprovação da segurança e eficácia no uso destas fontes naturais (YANG et al, 2017).

O Brasil possui uma grande variedade de ecossistemas e abrigos na região amazônica, que é a maior floresta tropical do mundo, bem como na vegetação de cerrado, conhecida como a savana mais biologicamente diversificada do mundo (OLIVEIRA et al., 2010). Devido a essa grande biodiversidade, incluindo a Mata Atlântica e outros biomas, muitas plantas medicinais brasileiras ainda não foram investigadas, o que abre a oportunidade de explorar essas plantas para a descoberta de novos metabólitos secundários com capacidade de interferir nas diferentes doenças provocadas em humanos (DUTRA et al., 2016; SHEPARD e RAMIREZ. 2011).

Sobre a diversidade da flora amazônica, podemos estudar e avaliar as diversas atividades de plantas como Bertholletia excelsa, espécie vegetal nobre e valiosa na Amazônia. Produto vegetal extrativo mais importante da região em valor econômico, ecológico, social e alimentar (MÜLLER, 1981). A primeira descrição da castanheira-do-Brasil (Bertholletia excelsa Humboldt Bonpland Kunth), data de 1808 decorrente das viagens de um rico geólogo alemão chamado Friedric Heinrich Alexander, Baron von Humboldt que decidiu pesquisar e descrever do ponto de vista científico, pela primeira vez, a flora de várias partes do mundo ainda inexploradas (CHAMBERS; HIGUCHI; SCHIMEL, 1998).

As castanheiras estão distribuídas em uma grande área geográfica de latitude de $5^{\circ} \mathrm{N}$ no alto Orinoco a $14^{\circ} \mathrm{S}$ no alto Madre de Dios RADAM-Brasil. (1973-1981). Pode ser encontrada na floresta de terra firme de solos na Amazônia e nas Guianas (MORI e PRACE, 1990). A castanheira mais antiga medida até o momento, continha $180 \mathrm{~cm}$ de diâmetro e 427 anos (BRIENEN \& ZUIDEMA, 2006). A árvore cresce em áreas de aproximadamente 400 metros acima do nível do mar, em temperaturas média entre 23,5 a $27,6^{\circ} \mathrm{C}$ e precipitação anual de 1.445 a $3.399 \mathrm{~mm}$, sendo típica de solos de oxisol e ultisol pobres em nutrientes e bem drenados (PERES e BAIDER, 1997; SHEPARD e RAMIREZ, 2011).

Sua maior concentração está na porção brasileira, principalmente no planalto que separa a bacia formada pelos afluentes do baixo Amazonas, alto Tocantins e alto Moju, e em terras altas ao 
norte do Rio Jarí, no estado do Pará e nos estados do Acre até o alto Beni e no Amapá (CURY et al, 2018). No Amazonas a castanheira é distribuída uniformemente em todo território, porém sua ocorrência é mais frequente ao longo das calhas dos rios Madeira, Purus e Solimões (CARDOSO et al., 2017).

Apresentam-se em bosques de 50 a 100 indivíduos conhecidos como castanhais (Portugueses), manchales ou castañales (Espanha), separados por distâncias consideráveis (1 km) de habitat compatível, com padrão de floração anual de elevada sincronia entre os indivíduos (PERES e BAIDER, 1997). Essa distribuição irregular levou Adolpho Ducke (1946), a sugerir que as castanheiras do Brasil poderiam ser plantações deixadas pelos antigos povos da Amazônia.

A espécie é responsável pela proteção de milhares de hectares de florestas tropicais, pois teve papel fundamental na inclusão dessas florestas na Categoria VI (áreas protegidas por recursos manejados), no Sistema de Classificação das Áreas Protegidas da IUCN (União Internacional para a Conservação da Natureza e dos Recursos Naturais) (COTTA et al., 2008). Essa categoria foi criada principalmente para legitimar as Reservas Extrativistas (Resex), como um modelo de conservação pautado no uso sustentável dos recursos naturais, além de inferir em uma variedade de características biológicas (HUBBELL, 1979).

Desta forma, a respeito deste potencial biológico da B. excelsa foi realizada uma pesquisade artigos disponibilizados em base de dados, sobre o uso na saúde das diversas partes daplanta. A pesquisa incluiu desde folhas, cascas até raízes, castanha e outros, com o intuito de compreender suas atividades biológicas descritas como leishmanicida, antimalárica, anti- tumoral, antioxidante, anti-inflamatória e outras em estudos in vitro e in vivo. Também foi relatada a sua importância econômica como fonte de renda de populações extrativistas no âmbito nacional e internacional.

\section{MATERIAL E MÉTODOS}

Foi realizada pesquisa eletrônica nas bases de dados Periódicos Capes, Google acadêmico, Scielo, Pubmed, Science Direct, Medline e Scopus utilizando palavras ecombinações de termos da seguinte maneira: "Bertholletia excelsa", Bertholletia excelsa, BERTHOLLETIA EXCELSA, "BERTHOLLETIA EXCELSA", castanheiras do Brasil, Bertholletia excelsa and/or biotechnology and Brazil nuts. Os limites colocados na varredura de dados foram trabalhos relacionados às castanheiras do Brasil, uso medicinal da planta, informações de importância econômica e estudos in vitro e in vivo com B. excelsa. 
Para seleção de trabalhos foram utilizados os seguintes critérios de inclusão: 1) artigos publicados nos principais periódicos das áreas: Saúde, Produtos naturais, Farmácia e Medicina 2) Idiomas: inglês, português e espanhol 3) trabalhos com estudo nas atividades biológicas de $B$. excelsa 4) revistas de alto impacto 5) ensaios biológicos in vitro e in vivo e acessos a teses e dissertações. A pesquisa bibliográfica que subsidiou a presente revisão foi baseada na consulta de trabalhos publicados encontrados na literatura, conforme as palavras-chaves supramencionadas. Para os critérios de exclusão foram delimitados outros idiomas, outros títulos de periódicos e demais termos e tópicos não correspondentes dos apresentados nas buscas das bases de dados.

Os resultados obtidos nesta revisão estão resumidos na figura 1. Na busca realizada em todas as bases de dados referidas, foram encontrados 38387 trabalhos publicados com osdescritores: Periódico Capes: "Bertholletia excelsa" 1094, Bertholletia excelsa 1101, BERTHOLLETIA EXCELSA 1696. Google acadêmico: Bertholletia excelsa and biotechnology 1910, Castanheiras do Brasil 17300, Bertholletia excelsa 13000, Scielo: Bertholletia excelsa 83, "Bertholletia excelsa” 78, Pubmed: Brazil nuts 523, “Bertholletia excelsa” 99, Bertholletia excelsa 185, Science direct: Bertholletia excelsa 586, "Bertholletia excelsa” 581, Medline e Scopus: Bertholletia excelsa 151. Deste total, foram avaliados título e resumo dos trabalhos paracritério de seleção e avaliação para continuidade do estudo. 107 trabalhos foram selecionados, e 58 escolhidos mais relevantes para nortear esta revisão baseados no tema do estudo, incluindo principalmente aqueles de importância no âmbito socioeconômico e fatores relacionados à saúde.

Figura 1: Organograma com os resultados das pesquisas em base de dados do estudo e seusresultados quantitativos com as palavras chaves da busca

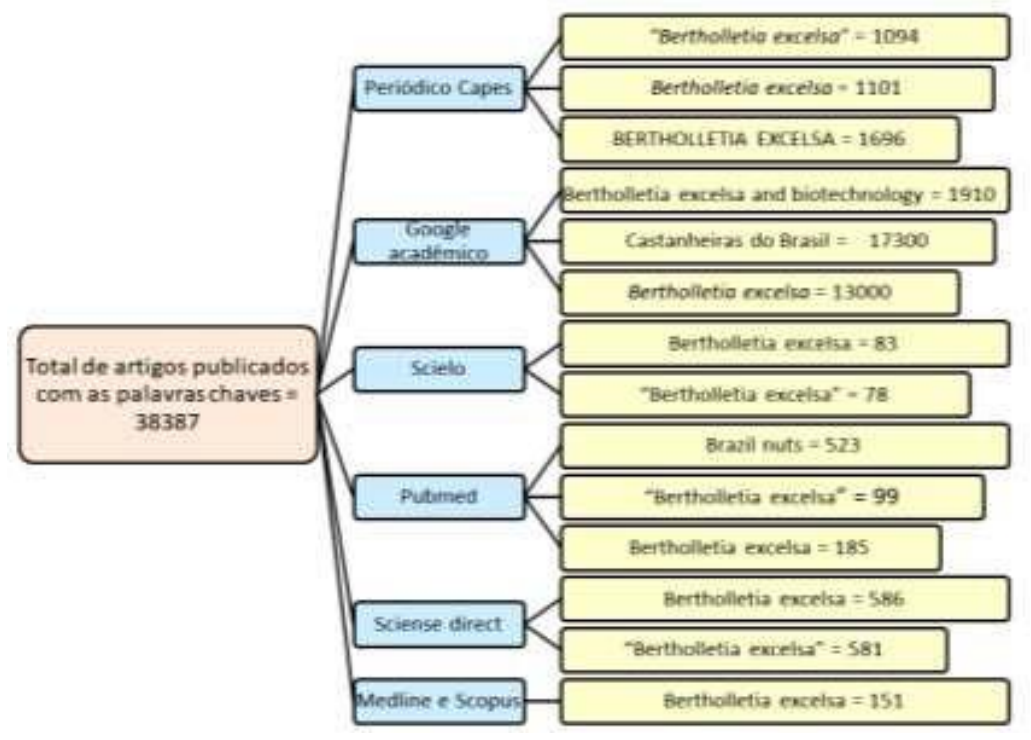

Fonte: Bancos bibliográficos da Internet (2018-2020 


\section{ASPECTOS BOTÂNICOS}

A castanha-do-Brasil é classificada botanicamente como pertencente à divisão: Angiospermae; classe: Dicotiledônea; ordem: Myrtiflorae; família: Lecythidaceae; gênero: Bertholletia; espécie: excelsa. A família inclui cerca de 200 espécies divididas em dez gêneros, No entanto, estudos genéticos recentes demonstram que são necessárias grandes revisões taxonômicas em pelo menos quatro delas (MORI et al., 2007). São todas árvores selvagens, sendo que a maioria cresce em locais úmidos próximos as águas do rio Amazonas e seus afluentes, desde as montanhas peruanas até o Atlântico. As árvores colossais atingem até $60 \mathrm{~m}$ de altura e $16 \mathrm{~m}$ de circunferência com DAP (Diâmetro de Altura do Peito) maior que 2 m, e vivem centenas de anos (PIRES, 1984). Possui caule cilíndrico, liso, desprovido de ramos até a fronde, casca escura e fendida, ramos encurvados nas extremidades (PACHECO; SCUSSEL, 2006).

A espécie $B$. excelsa é única nas Lecythidaceae, seu fruto tem forma de cápsula globosa quase esférica, medindo de 8 a $15 \mathrm{~cm}$ de diâmetro. Sendo visível na parte superior, o vestígio docálice, apresentando casca espessa, lenhosa, dura e de cor castanha (MAUES, 2002). Todas as outras Lecythidaceae com frutas que caem no chão na maturidade têm uma frágil parede de frutos (pericarpo), que logo se abre, ou então uma "tampa" que cai do opérculo (abertura semelhante a um cálice), permitindo que as sementes se dispersem (JOHN; SHAHIDI, 2010). A tampa opercular da castanha-doBrasil cai para dentro, em vez de fora, bloqueando a abertura que, em qualquer caso é muito pequena (cerca de $1 \mathrm{~cm}$ de diâmetro) para liberar as sementes, que têm em média 2,0 cm de largura por 5,0 cm de comprimento (PERES e BAIDER, 1997).

As folhas da castanheira são simples, espaçadas, alternadas, pecioladas, verde escuras, brilhosas na parte superior e pálidas na inferior, apresentam seis pétalas brancas ou brancacentas, tubulosas, grandes, dispostas em panículas terminais e eretas (THOMSON et al., 2008). Suas flores são alógamas polinizadas por abelhas grandes (principalmente dos gêneros Bombus, Centris, Xylocopa, Epicharis e Eulaema), capazes de voar longas distâncias (> $20 \mathrm{~km}$ ), garantindo assim um extenso fluxo gênico entre árvores e populações distantes. Essas flores são cobertas por uma das pétalas, que ao longo do tempo necessita ser levantadas pelos polinizadores durante a polinização. Essas mesmas flores, são dispostas por inflorescência euma ou duas se abrem por dia (STOCKLER-PINTO, 2010). 
Suas sementes requerem de 12 a 18 meses de armazenamento em condições úmidas para germinação, em comparação com a germinação quase instantânea para a maioria das outras espécies da família Lecythidaceae (MORI e PRANCE, 1990). A castanheira é uma árvore dominante no dossel superior que se regenera naturalmente nas lacunas da floresta (SUN; LEUNG, TOMIC, 1987). Essas áreas de distúrbios florestais de pequena escala, fornecem os níveis mais altos de luz aparentemente necessários para que a castanha do Brasil atinja o tamanho reprodutivo (MORI e PRANCE, 1990).

Sua madeira é muito útil para construção principalmente naval e civil, assim como também, com a madeira se produz celulose de boa qualidade para fabricação de papéis, embora seja ilegal derrubar castanheiras no Brasil (CARDARELLI; OLIVEIRA, 2000). Já com sua casca, pode-se fazer um tipo de fibra que apresenta uma cor tipicamente acinzentada que é utilizada como estopa de calefação, do ouriço se faz carvão de elevado poder calorífico e da amêndoa se extrai um óleo de excelente qualidade, tanto para fabricação de cosméticos quanto para alimentação (KITAMURA e MULLER, 1984).

A castanha é um alimento que retém selênio em sua composição, incorporando-o às selenoproteínas estão envolvidas nas funções enzimáticas do metabolismo dos antiinflamatórios, hormônios da tireóide e antioxidantes (FREITAS et al., 2008; SCHOMBURG e KÖHRLE, 2008). Têm em sua matriz, substâncias bioativas como $\alpha$ $\beta$-tocoferol, compostos fenólicos, folato, magnésio, cálcio, potássio, zinco, proteínas e ácidos graxos mono e poli-insaturados (KOCYGIT; KOYLU; KELES, 2006; ROS, 2009; ROS et al, 2004). É rica em lipídeos (60-70\%), proteínas de alto valor biológico (15-20\%), vitaminas, ácido palmítico,esteárico, linoleico, linolênico, sendo que a fração lipídica dos ácidos graxos saturados não ultrapassa 25\% de seu total (FREITAS et al., 2007).

Apresenta altos níveis de aminoácidos como cisteína e metionina considerados a fonte mais rica desses aminoácidos essenciais (ANTUNES, 1975; SUN; LEUNG; TOMIC, 1987). A fração de albumina $2 S$ da castanha-do-Brasil, contém altos níveis de metionina e cisteína em uma análise de proteínas de baixo peso molecular segundo Youle \& Huang, (1981). Após esse achado houve um interesse crescente no valor nutricional da castanha-do-Brasil, pois muitas proteínas vegetais são deficientes nesses aminoácidos essenciais (DE CLERCQ et al., 1990). 
O óleo da castanha é usado também como lubrificante na aviação e em componentes eletrônicos, pelas suas propriedades antioxidantes e também na fabricação de doces finos in natura. Da prensagem da castanha pode ser obtido o óleo e o leite de castanha, usado na elaboração de iguarias culinárias (PERES e BAIDER, 2009). Seu óleo apresenta 13,8\% deácido palmítico, 8,7\% de ácido esteárico, 31,4\% de ácido oleico e 45,2\% de ácido linoleico,além de pequenas quantidades dos ácidos mirístico e palmitoléico (FREITAS et al., 2007).

\section{IMPORTÂNCIA ECONÔMICA}

As castanheiras são de importância econômica em países como Brasil, Peru e Bolívia, sendo considerada fonte econômica para diversas famílias extrativistas, representando em até 70\% da economia total das regiões produtoras (ALMEIDA, 1963). A cadeia produtiva apresenta variações conforme as tecnologias adotadas pelo extrativista ou pela usina, e é executada em função da finalidade em se obter a castanha com e sem casca (ANSELMO et al., 2018).

A produção extrativa vegetal da Amazônia encontrava fluxo comercial nos mercados europeus, desde a época da colonização do Brasil pelos portugueses. De fato, a foz do rio Amazonas era uma região onde se praticava um intenso comércio. Muitas vezes ilegal de produtos regionais, os quais eram cobiçados por ingleses, franceses, holandeses e irlandeses. Passado um pouco mais de um século, alguns produtos daquela época continuam presentes na pauta do comércio exterior da Amazônia, por exemplo, a castanha, madeiras, óleos, peixes e essências vegetais.

A castanha-do-Brasil produzida é comercializada no exterior, sendo que os maiorescompradores são os Estados Unidos, a Inglaterra, França, Alemanha e Itália. No entanto, a comercialização da castanha dentro do país é uma importante fonte de renda para milhares de povos indígenas que vivem na Amazônia (JOHN e SHAHIDI, 2010).

Os principais países importadores de castanha-do-Brasil são: Itália, Alemanha, Estados Unidos, Reino Unido e Japão. Apesar das barreiras sanitárias estabelecidas por esses países, principalmente a partir do ano de 2003, a produção total do Brasil em 2006 foi de $28.806 \mathrm{~T}$, com uma participação da região Norte de $98,35 \%$ desse total (IBGE/SIDRA, 2007). 
Em 1933 a produção brasileira variou de 3557 toneladas em 1944 a 104.487 toneladas em 1970. A baixa produção no início de 1940, foi causada pela demanda reduzida por dois dos maiores consumidores, Estados Unidos e Grã-Bretanha durante a Segunda Guerra Mundial, com média de produção anual de 40.000 toneladas (SÁNCHEZ, 1973). Já em 1984, a produção brasileira de castanha era de $90 \%$ da produção mundial, até 1990 o país ocupava a liderança no mercado mundial com $80 \%$ do comércio internacional e produção maior que 51.000 toneladas (NÉMETH, 2013).

Após a expansão da produção e a comercialização da castanha-do-Brasil no exterior em 1866, com abertura dos portos da Amazônia, a coleta de castanha passou a ser uma importante atividade econômica na Amazônia, principalmente nas regiões de Manaus e Belém (CHUNHIENG et al., 2004).

As exportações a castanha-do-Brasil sofreram também uma retração significativa. O balanço comparativo entre 2000 e 2001 registrou uma queda nas exportações brasileiras de castanha com casca que chega perto de 60\%. O Pará obteve pior desempenho, porém embora se mantenha a liderança no ranking de Estados exportadores, sofreu uma redução superior a $62 \%$.O preço da amêndoa também caiu de US\$2,64 para US\$1,83 o quilo. Em termos nacionais, a exportação caiu de pouco mais de US\$ FOB (Free On Board) 11.149.679 em 2001, contra US\$ FOB 27.686.194, em 2000. No Pará, US\$ FOB 13.175.113 somente de casca sem casca e mais US\$ FOB 8.244.044 do produto com casca (FARIA, 2001; ALICE-WEB, 2006).

De acordo com dados da Produção da Extração Vegetal e da Silvicultura - PEVS, ao qualconstitui a principal fonte de estatísticas sobre o acompanhamento sistemático da exploraçãodos recursos florestais em todo o Território Nacional do IBGE, a produção brasileira da castanha-do-Brasil, alcançou um superávit em 2011 de 42.152T, uma mediana em 2015 com 40.643T e uma menor produção em 2016 de 34.664 toneladas como observado na figura 2 (IBGE/PEVS, 2016). 
Figura 2: Produção Brasileira da castanha-do-Brasil em toneladas

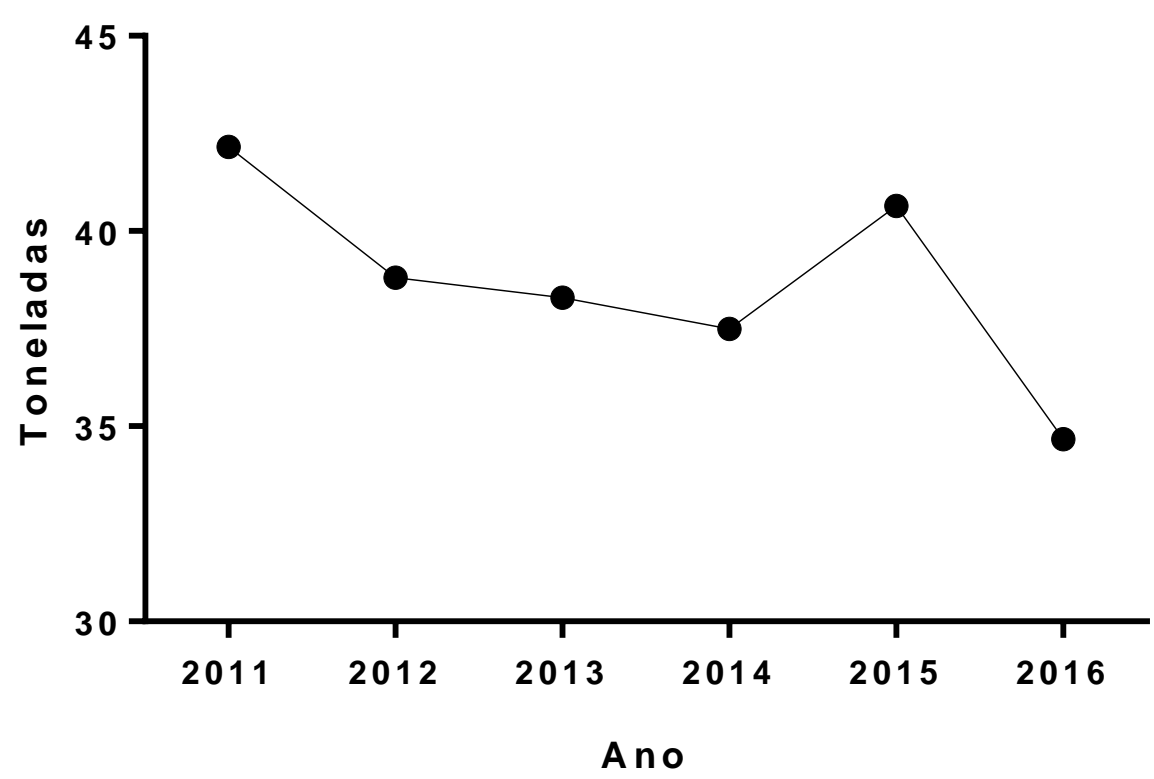

Fonte: Instituto Brasileiro de Geografia e Estatística (IBGE). Produção da extração vegetal e dasilvicultura PEVS. (2016).

\section{APLICAÇÕES PARA ÁREA DA SAÚDE}

Vários estudos relacionam diversas atividades biológicas com o uso de partes da planta (casca do caule, fruto, folhas, fruto e castanhas) de B. excelsa como demostrado na tabela 1. Segundo Ribeiro et al (2018), as plantas medicinais brasileiras são consideradas um suprimento promissor, no que tange sua biodiversidade, principalmente em relação ao seu potencial anti- inflamatório como constatado em seus estudos com a diminuição de marcadores inflamatórios como as interleucinas, fator de transcrição NF$\mathrm{k} \beta$, prostaglandinas, ciclooxigenases e espécies reativas de oxigênio.

Esta atividade anti-inflamatória de $B$. excelsa, também foi demostrada nos estudos de Colpo e colaboradores (2014), os quais foi investigado o efeito de uma única dose de castanha (20 ou 50g) nos marcadores inflamatórios em indivíduos saudáveis, testados antes e após o consumo das nozes. As enzimas renais (ureia/creatinina) e hepáticas (TGO, TGP, GGT, fosfatase alcalina), não apresentaram qualquer alteração bioquímica indicando ausência detoxicidade hepática e renal. Já os valores séricos de IL-1 $\beta$, IL-6, TNF- $\alpha$ e IFN-y foram diminuídos, enquanto que os valores da interleucina-10 (antiinflamatória) foram significativamente aumentados $(p<0,05)$. Demostrando que o 
consumo em longo prazo da castanha-do-Brasil, pode diminuir os marcadores inflamatórios em indivíduos saudáveis.

Com a suplementação diária da castanha por três meses Stockler-Pinto e colaboradores (2015), puderam observar que os níveis plasmáticos de 8-OHdG e 8isoprostano diminuíram, ea atividade dos níveis de GPx e selênio no plasma aumentaram significativamente, promovendo uma resposta anti-inflamatória e antioxidante em pacientes com aporte de hemodiálise. Em se tratando de resposta antioxidativa de $B$. excelsa, Huguenin et al (2015), avaliaram pacientes hipertensos e dislipidêmicos com uso de $13 \mathrm{~g}$ diária de castanha-do-Brasil. Constatou-se aumento significativo nas taxas de selênio plasmático ( $\mathrm{Se}$ ), aumento da atividade da enzima antioxidante glutationa peroxidase (GPx), capacidade de antioxidante total (TAC) e redução dosníveis de LDL oxidado nesse grupo de pacientes.

Quanto atividade antiparasitária da espécie em estudo, extratos brutos e frações da casca do caule de $B$. excelsa promoveram atividade tripanocida em ensaios in vivo com animais infectados por T. cruzi, reduzindo em 90,3\% os parasitas (CAMPOS et al, 2005). B. excelsa apresentou atividade antimalárica em cultura in vitro de $P$. falciparum, com valor de CI50\% abaixo de $1,6 \mu \mathrm{g} / \mathrm{mL}$ frente a outros extratos testados (OLIVEIRA et al., 2015).

Atividade anti-carie com o uso do óleo das castanhas de B. excelsa foi descrita por Filogônio e colaboradores (2011), após monitoramento de indivíduos em uso de (dentifrício+óleo vegetal de $B$. excelsa). Foi possível constatar uma melhora e controle do biofilme dental e com isso prevenindo das doenças periodontais. No que se refere atividade anti-tumoral de B. excelsa, Ip \& Lisk (1994), em modelos com animais avaliaram a prevenção do câncer mamário, após suplementação com castanhas em doses de $1-3 \mu \mathrm{g} / \mathrm{g}$.

Tabela 1 - Principais atividades biológicas de Bertholletia excelsa abordadas na literatura

\begin{tabular}{|l|l|l|}
\hline \multicolumn{1}{|c|}{ ATIVIDADE } & \multicolumn{1}{|c|}{ RESULTADO } & REFERÊNCIA \\
\hline $\begin{array}{l}\text {-Avaliação do perfil antioxidante } \\
\text { após suplementação da } \\
\text { castanha- do-Brasil }\end{array}$ & $\begin{array}{l}\text {-Uso os ensaios enzimáticos de } \\
\text { varredura deradicais livres com ORAC, } \\
\text { DPPH, TEAC com diminuição dos } \\
\text { níveis de estresse oxidativo }\end{array}$ & $\begin{array}{l}\text { SOHN e } \\
\text { SHAHIDI, }\end{array}$ \\
\hline $\begin{array}{l}\text {-Atividade tripanocida in } \\
\text { vitro contra a forma } \\
\text { promastigota de Tripanosoma }\end{array}$ & $\begin{array}{l}\text { - Extratos brutos da casca do caule de } \\
\text { B. excelsa reduzira significativamente em } \\
100 \% \text { o número de parasitos }\end{array}$ & $\begin{array}{l}\text { CAMPOS et } \\
\text { al.,2005 }\end{array}$ \\
\hline
\end{tabular}




\begin{tabular}{|c|c|c|}
\hline cruzi & & \\
\hline $\begin{array}{l}\text {-Determinar as condições } \\
\text { ótimas da atividade da } \\
\text { lipoxigenase }(\mathrm{LOX}) \text { em } B \text {. } \\
\text { excelsa }\end{array}$ & $\begin{array}{l}\text {-Detecção das lipoxigenases LOX-2 e/ou } \\
\text { LOX-3 em pH 6,5 na castanha-do-Brasil }\end{array}$ & $\begin{array}{l}\text { FERREIRA et } \\
\text { al., } 2011\end{array}$ \\
\hline $\begin{array}{l}\text { - Avaliar as concentraçõesde } \\
\text { selênio, atividade da glutationa } \\
\text { peroxidase e perfil lipídico do } \\
\text { grupo em estudo }\end{array}$ & $\begin{array}{l}\text { - Houve aumento de Se e GPx no plasma } \\
\text { daspacientes com diminuição dos } \\
\text { parâmetros lipídicos reduzindo assim } \\
\text { os riscos cardiovasculares }\end{array}$ & $\begin{array}{l}\text { COMINETTI } \\
\text { et al., } 2012\end{array}$ \\
\hline $\begin{array}{l}\text {-Potencial antioxidante e anti } \\
\text { inflamatório da castanha-do- } \\
\text { Brasil em pacientes que fazem } \\
\text { hemodiálise }\end{array}$ & $\begin{array}{l}\text {-Aumento no nível de selênio (Se) e } \\
\text { glutationa peroxidase (GPx), diminuição } \\
\text { dos níveis de citocinas inflamatórias (TNF- } \\
\alpha \text { e IL-6) e 8-OHGd no plasma. }\end{array}$ & $\begin{array}{l}\text { STOCKLER- } \\
\text { PINTO et al, } \\
2014\end{array}$ \\
\hline $\begin{array}{l}\text {-Avaliar os níveis plasmáticos } \\
\text { deselênio (Se) e dos } \\
\text { hormônios da tireóide (T4 e } \\
\text { T4) nos pacientesem uso de } \\
\text { hemodiálise }\end{array}$ & $\begin{array}{l}\text { - Houve a detecção de Selênio nos } \\
\text { pacientesapós suplementação com } \\
\text { castanha-do-Brazil e regulação dos } \\
\text { níveis tireoidianos e da atividade da } \\
\text { glutationa peroxidase (GPx) }\end{array}$ & $\begin{array}{l}\text { STOCKLER- } \\
\text { PINTO et al, } \\
2015\end{array}$ \\
\hline $\begin{array}{l}\text {-Avaliar a regulação dos } \\
\text { biomarcadores do câncer de } \\
\text { coloretal humano com consumo } \\
\text { diário da castanha }\end{array}$ & $\begin{array}{l}\text { - Aumento significativo de } \\
\text { selênio,selenoproteínas retal P (SePP), } \\
\beta \text {-catenina em RNA. Redução dos níveis } \\
\text { de DNMT1 e NF-k } \beta \text { da inflamação }\end{array}$ & HU et al., 2016 \\
\hline $\begin{array}{l}\text {-Investigar a redução da lesão } \\
\text { renal por isquemia-reperfusão, } \\
\text { inflamação e estresse oxidativo } \\
\text { após suplementação com } \\
\text { castanha-do-Brasil }\end{array}$ & $\begin{array}{l}\text { - Redução dos parâmetros de função renal } \\
\text { (ureia, creatinina, fósforo plasmático), } \\
\text { elevação da depuração da creatinina e } \\
\text { volume urinário com redução da } \\
\text { proteinúria e expressão de iNOS. }\end{array}$ & $\begin{array}{l}\text { ANSELMO et } \\
\text { al., } 2018\end{array}$ \\
\hline $\begin{array}{l}\text {-Diminuição da peroxidação } \\
\text { lipídica contribuindo para } \\
\text { a redução do estresse oxidativo }\end{array}$ & $\begin{array}{l}\text {-Diminuição dos parâmetros } \\
\text { antropométricos,pressão arterial, } \\
\text { bioquímicos e oxidativos }\end{array}$ & $\begin{array}{l}\text { COSTA et al, } \\
2020\end{array}$ \\
\hline $\begin{array}{l}\text { - Investigar o efeito da castanha- } \\
\text { do-Brasil nos níveis plasmáticos } \\
\text { de selênio, glutationa } \\
\text { peroxidase e hormônios da } \\
\text { tireoide }\end{array}$ & $\begin{array}{l}\text { - Com suplementação diária de } 9.42 \mathrm{~g} \text { de } \\
\text { castanha foi possível observar aumento nos } \\
\text { níveis de selênio e GPx, porém não houve } \\
\text { interferência nos hormônios tireoidianos }\end{array}$ & $\begin{array}{l}\text { YINGXIN et } \\
\text { al.,2020 }\end{array}$ \\
\hline
\end{tabular}

\section{CONSIDERAÇÕES FINAIS}

A presente revisão norteou a pesquisa dos diversos achados econômicos, e uso na saúde de B. excelsa na literatura, em consulta aos bancos de dados presentes no estudo para subsidiar nossa pesquisa. Foi descrito a origem da espécie, dimensões, localização e seus aspectos botânicos. Pode-se observar, uma grande importância no cenário 
econômico promovido por $B$. excelsa, representando mais de $80 \%$ da renda de populações extrativistas e o interesse crescente na demanda do mercado internacional.

Em conclusão, apontamos as atividades biológicas de $B$. excelsa como antiinflamatória, anti-tumoral, antiparasitária, antioxidante e outros. Destacando a importância de se realizar mais ensaios experimentais, na tentativa de elucidar outras atividades e novos mecanismos de ação desta espécie tão valiosa presente na flora Amazônica. Assim como, é fundamental na fonte de renda econômica, ecológica e medicinal de tantas populações. Para enfim, torná-la um alvo terapêutico promissor no uso das diversas doenças que assolam a sociedade

\section{REFERENCIAS}

ALMEIDA, C.P. Castanha do Pará: sua exportação e importação na economia Amazonica. edicções S.I.A. Estudos Brasileiros 19: 1-86, 1963.

ANSELMO, N.A. et al. Prior intake of Brazil nuts attenuates renal injury induced by ischemia andreperfusion. Jornal brasileiro de nefrologia: orgao oficial de Sociedades Brasileira e Latino-Americana de Nefrologia, v. 40, n. 1, p. 10-17, 2018.

ANTUNES, A.J. Protein supplement of navy bean with Brazil nuts. PhD Thesis, Department of Food Science and Human Nutrition, State University of Michigan, East Lansing, MI, USA, 1975.

BALICK, M.J. Useful plants of Amazonia: A resource of global importance. Amazonia Pergamon Press, p. 339-368, 1985.

BRIENEN, R.J.W.; ZUIDEMA, P.A. Lifetime growth patterns and ages of bolivian rain forest treesobtained by tree ring analysis. Journal of Ecology, v. 94, n. 2, p. 481493, 2006.

CAMPOS, F.R.; JANUÁRIO, A.H.; ROSAS, L.V.; NASCIMENTO, S.K.R.; PEREIRA, P.S.; FRANÇA,S.C.; CORDEIRO, M.S.C.; TOLDO, M.P.A., ALBUQUERQUE, S. Trypanocidal activity of extracts and fractions of Bertholletia excelsa. Fitoterapia, v. 76, n. 1, p. 26-29, 2005.

CARDARELLI, H.R.; OLIVEIRA, A.J. Conservação do leite de castanha-do-Pará. Scientia Agricola, v. 57, n. 4, p. 617-622, 2000.

CARDOZO, L.F.M.F.; STOCKLER-PINTO, M.B.; MAFRA, D. "Brazil nut consumption modulates Nrf2 expression in hemodialysis patients: A pilot study". Molecular Nutrition and Food Research, v. 60, n. 7, p. 1719-1724, 2016. 
CARDOSO, B.R.; DUARTE, G.B.S.; REIS, B.Z.; COZZOLINO, S.M.F. "Brazil nuts: Nutritional composition, health benefits and safety aspects". Food Research International, v. 100, p. 9-18, 2017.

COLPO, E.; DALTON D.A.C.; VILANOVA, L.G.B.R.; MARTA, M.M.F.; DUARTE, I.L.G.; FARIAS, D.F.M.; MARIANO, D.O.C. "Brazilian nut consumption by healthy volunteers improvesinflammatoryparameters”. Nutrition, v. 30, n. 4, p. 459-65, 2014.

COTTA, J.N.; KAINER, K.A.; WADT, L.H.O.; STAUDHAMMER, C.L. Shifting cultivation effects on Brazil nut (Bertholletia excelsa) regeneration. Forest Ecology and Management, v. 256, n. 2, p. 28-35, 2008.

COMINETTI, C.; BORTOLI, M.C.; PURGATTO, E.; ONG, T.P.; MORENO, F.S.; GARRIDO, A.B.; COZZOLINO, S.M.F. Associations between glutathione peroxidase-1 Pro198Leu polymorphism, selenium status, and DNA damage levels in obese women after consumption of Brazil nuts. Nutrition, v. 27, n. 9, p. 891-896, 2011.

COMINETTI, C.; BORTOLI, M.C.; GARRIDO, A.B.; COZZOLINO, S.M.F. "Brazilian nutconsumption improves selenium status and glutathione peroxidase activity and reduces atherogenic risk in obese women". Nutrition Research, v. 32, n. 6, p. 403-4077, 2012.

CURY, M.F.R. et al. Inflammation and kidney injury attenuated by prior intake of Brazil nuts in the process of ischemia and reperfusion. Jornal brasileiro de nefrologia: Sociedades Brasileira e Latino-Americana de Nefrologia, v. 40, n. 4, p. 312-318, 2018.

CHAMBERS, J.Q.; HIGUCHI, N.; SCHIMEL, J.P. Ancient trees in Amazonia. Nature, v. 391, p. 135-136, 1998.

CHUNHIENG, T. et al. Study of selenium distribution in the protein fractions of the Brazil nut, Bertholletia excelsa. Journal of Agricultural and Food Chemistry, v. 52, n. 13 , p. 4318-4322,2004.

DE CLERCQ, A.; VANDEWIELE, M.; VAN DAMME, J.; GUERCHE, P.; VAN MONTAGU, M.; VANDEKERCHHOVO, J.; KREBBUS, E. Stable accumulation of modified $2 \mathrm{~S}$ albumin and storage proteins with higher methionine contents in transgenic plants. Plant Physiology, v. 94, p. 970- 979, 1990.

DUCKE, A. Plantas de cultura pré-colombiana na Amazônia brasileira. Boletim Técnico do Instituto Agronomico do Norte, v. 8, p. 2-24, 1946.

DUTRA, R.C.; CAMPOS, M.M.; SANTOS, A.R.S.; CALIXTO, J.B. "Medicinal plants in Brazil: Pharmacological studies, drug discovery, challenges and perspectives". Pharmacological Research, v. 112, p. 4-29, 2016.

FERREIRA, F.N.; XAVIER, E.M.P.; PINTO, A.S.; POMPEU, D.R. "Avaliação da atividade dalipoxigenase na castanha do Brasil (Bertholletia excelsa)". Boletim Centro de Pesquisa de Processamento de Alimentos, v. 29, n. 1, p. 1-8, 2011.

FILOGÔNIO, C.F.B.; SOARES, R.V.; HORTA, M.C.R.; PENIDO, C.V.S.R.; CRUZ, R.A. "Effect of vegetable oil (Brazil nut oil) and mineral oil (liquid petrolatum) on dental biofilm control”. Brazilian OralResearch, v. 25, n. 6, p. 556-61, 2011. 
FREITAS, S.P.; SILVA, O.F.; MIRANDA, I.C.; COELHO, M.A.Z. Extração e fracionamento simultâneo do óleo da castanha-do-Brasil com etanol. Ciência e Tecnologia de Alimentos, v. 27, p. 14-17, 2007.

FREITAS, S.C.S.; GONÇALVES, E.B.; ANTONIASSI, R.; FELBERG I.; OLIVEIRA, S.P.D. Meta-analysis of selenium content in Brazil nuts. Braz J Food Technol, v. 11, p. 54-62, 2008.

GONZAGA, Irland Barroncas. Avaliaçäo nutricional relativa ao selênio em crianças com dieta enriquecida de castanha-do-Brasil (Bertholletia excelsa, L). Tese de

Doutorado. Universidade deSäo Paulo. Faculdade de Ciências Farmacêuticas, 2002.

HOLBEN, D.H.; SMITH, A.M. The diverse role of selenium with selenoproteins: a Review. J. Am.Diet. Assoc, v. 99, p. 836-843, 1999.

HU, Y.; GRAEME, H.; MCINTOSH, RICHARD, K.L. L.; SOMASHEKAR, R.; MENG, X.Q.; GOPALSAMY, G.; BAMBACA, L.; MCKINNON, R.A.; YOUNG, G.P. "Supplementation with Brazilnuts and green tea extract regulates targeted biomarkers related to colorectal cancer risk in humans". British Journal of Nutrition, v. 116, n. 11, p. 1901-11, 2016.

HUGUENIN, G.V.B.; GLAUCIA, M.M.; OLIVEIRA, A.S.B.M.; SAINT'PIERRE, T.D.; GONÇALVES,R.A.; PINHEIRO-MULDER, A.R.; TEODORO, A.J.; LUIZ, R.R.; ROSA, G. "Improvement of antioxidant status after Brazil nut intake in hypertensive and dyslipidemic subjects". NutritionJournal, v. 14, n. 1, p. 1-10, 2015.

HUBBELL, S.P. Tree dispersion, abundance, and diversity in a tropical dry forest. Science,v. 203, n. 4387, p. 1299-1309, 1979.

IP, C.; LISK, D.J. "Bioactivity of Selenium From Brazil Nut for Cancer Prevention and Selenoenzyme Maintenance". Nutrition and Cancer, v. 21, n. 3, p. 203-212, 1994.

JOHN, J.A.; SHAHIDI, F. "Phenolic compounds and antioxidant activity of Brazil nut (Bertholletiaexcelsa)". Journal of Functional Foods, v. 2, n. 3, p. 196- 209, 2010.

KAINER, K; DURYEA, M.L.; MALAVASI, M.M.; SILVA, E.R.; HARRISON, J. Moist sorrabe of Brasil nut seeds for improved germination and nursery management. Forest ecology and management, v. 116, p. 207-217, 1999.

KANASHIRO, M.; HARRIS, S.A., SIMONS, A. RAPD diversity in Brazil nut (Bertholletia excelsa Humb. \& Bonpl.: Lecythidaceae). Silvae Genetica, v. 46, n. 4, p. 219-223, 1997.

KITAMURA, P.C.; MULLER, C.H. Castanhais nativos de Marabá-PA: Fatores de depressão e bases para a sua preservação. EMBRAPA, Centro de Pesquisas Agropecuário do Trópico Úmido. Documentos 30: 1-32, 1984.

KOCYGIT, A.; KOYLU, A.A.; KELES, H. Effects of pistachio nuts consumption on plasma lipid profile and oxidative status in healthy volunteers. Nutr Metab

Cardiovasc Dis, v. 16, n. 3, p. 202-209, 2006.

MAUÉS, M.M. Reproductive phenology and pollination of the Brazil nut tree

(Bertholletia excelsaHumb. \& Bonpl. Lecythidaceae) in Eastern Amazonia. In: P. 
KEVAN \& V. L. IMPERATRIZ FONSECA (Eds.): Pollinating bees: the conservation link between agriculture and nature, p.245-254. Ministério do Meio Ambiente, 2002.

MORI, S.A.; SWARTHOUT, D. Brazil nut family (Lecythidaceae) in the New World. In Encyclopedia of Earth, ed. C. J. Cleveland and D. Swarthout. Environmental InformationCoalition, National Council for Science and the Environment, Washington, 2007.

MORI, S.A.; PRANCE, G.T. Taxonomy, ecology, and economic botany of the Brazil nut (Bertholletia excelsa Humb. \& Bonpl.: Lecythidaceae). Advances in Economic Botany, v. 8, p.130-150, 1990.

MOMČILOVIĆ, B., PREJAC, J.; VIŠNJEVIĆ, V.; BRUNDIĆ, S.; SKALNY, A.A.; MIMICA, N. "Highhair selenium mother to fetus transfer after the Brazil nuts consumption". Journal of Trace Elements in Medicine and Biology, v. 33, p. 110-113, 2016.

MÜLLER, C.H. Castanha-do-Brasil: Estudos agronômicos. EMBRAPA/Centro de Pesquisa Agropecuária do Trópico Úmido, Belém, Pará, 1981.

MYERS, G.P.; NEWTON, A.C.; MELGAREJO, O. The influence of canopy gap size on natural regeneration of Brazil nut (Bertholletia excelsa) in Bolivia. Forest Ecology and Management,v.127, n.1-3, p.119-128. 2000.

NELSON, B.W.; ABSY, M.L.; BARBOSA, E.M.; PRANCE, G.T. Observations on flower visitors to Bertholletia excelsa H.B.K, and Couratari tenuicarpa A. C. Sm. (Lecythidaceae). Acta Amazónica, v. 15, p.1-2, 1985.

NÉMETH, A. et al. The relationship of selenium tolerance and speciation in Lecythidaceae species. Metallomics, v. 5, n. 12, p. 1663-1673, 2013.

O’MALLEY, D.M.; BUCKLEY, D.P.; PRANCE, G.T.; BAWA, K.S. Genetics of Brazil nut (Bertholletiaexcelsa Humb. \& Bonpl.: Lecythidaceae): II. Mating system. Theoretical and Applied Genetics, v. 76, n. 6, p. 929-932, 1988.

OLIVEIRA, D.R.; KRETTLI, A.U.; AGUIAR, A.C.C; LEITÃO, G.G.; VIEIRA, M.N.; MARTINS, K.S. LEITÃO, S.G. "Ethnopharmacological evaluation of medicinal plants used against malaria by quilombola communities from Oriximiná, Brazil”. Journal of Ethnopharmacology, v. 173, n. 424-434. 2015.

OLIVEIRA, D.R.; LEITÃO, S.G.; O’DWYER, E.C.; LEITÃO, G.G. ARQMO, Authorization of the traditional knowledge associated access for bioprospecting purposes: the case of UFRJ and the association of the Oriximiná quilombola communities - ARQMO. Rev. Fitos, v. 5, p. 59-76, 2010b.

PACHECO, A.M., SCUSSEL, V.M. Castanha-do-Brasil: da floresta tropical ao consumidor. Florianópolis, SC: Editograf, 2006.

PERES, C.A.; BAIDER, C. Seed Dispersal, Spatial Distribution and Population Structure of Brazilnut Trees (Bertholletia excelsa) in Southeastern Amazonia. Ecology Tropical. http://www.jstor.o". Structure, v. 13, n. 4, p. 595-616, 2009.

PIRES, J.M. The Amazonian forest. in H. Sioli, ed., The Amazon: Limnology and landscape ecology of a mighty tropical river and its basin, p. 581- 602, 1984. 
PINTO, R.; CÍNTIA, M.; PUSHKAR, S.B. "Functionality of succinylated Brazil nut (Bertholletia excelsa HBK) kernel globulin”. Plant Foods for Human Nutrition, v.60, n.1, p.1-6. 2005.

RADAM-Brasil. Levantamento de recursos naturais: Geologia, geomorfologia, solos, vegetação, uso potencial da terra (22 volumes). Rio de Janeiro: Ministério de Minas e Energia, Departamento Nacional de Produção Mineral. (1973-1981).

RIBEIRO, V.P.; CAROLINE A.; MOHAMED ABD, E.S.; BASTOS, J.K. "Brazilian medicinal plants with corroborated anti-inflammatory activities: A review".

Pharmaceutical Biology, v. 56, n. 1, p. 253-268, 2018.

ROS, E. Nuts and novel biomarkers of cardiovascular disease. Am J Clin Nutr, v. 89, p. 1649S-1656S, 2009.

ROS, E.; NUNEZ, I.; PEREZ-HERAS, A.; SERRA, M.; GILABERT, R.; CASALS, E.; DEULOFEU, R. Awalnut diet improves endothelial function in hypercholesterolemic subjects: a randomizedcrossover trial. Circulation, v. 109, p. 1609-1614, 2004.

SÁNCHEZ, J.S. Explotación y comercialización de la castaña en Madre de Dios. Ministerio deAgricultura, Dirección General de Forestal y Caza, Infprme n30. Lima, Peru, 1973.

SILVA, E.; COSTA, L.M.; MELO, M.L.P.; REIS, F.V.F.; MONTEIRO, M.C.; SANTOS, S.M.; GOMES, B.A.Q.; SILVA, L.H.M. "Comparison of the effects of Brazil nut oil and soybean oil on the cardiometabolic parameters of patients with metabolic syndrome: A randomized trial".

Nutrients, v. 12, n. 1, p. 1-14, 2020.

SUN, S.S.M.; LEUNG, F.W.; TOMIC, J.C. Brazil nut (Bertholletia excelsa H. B. K.) proteins: fractionation, composition and identification of a sulfur rich protein. Journal of Agricultural and Food Chemistry, v. 35, p. 232-235, 1987.

STOCKLER-PINTO, M.B.; MAFRA, D.; MORAES, C.; LOBO, J.; BOAVENTURA, G.T.; FARAGE, N.E.; SILVA, W.S.; COZZOLINO, S.F.; MALM, O. "Brazil nut (Bertholletia excelsa, H.B.K.) improves oxidative stress and inflammation biomarkers in hemodialysis patients”. Biological Trace Element Research, v. 158, n. 1, p. 105-12. 2014.

STOCKLER-PINTO, M.B., CARRERO, J.J.; WEIDE, L.C.C.; COZZOLINO, S.M.F.; MAFRA, D. "Efecto de la suplementación de selenio a través de la nuez de Brasil (Bertholletia excelsa, HBK) en los niveles de hormonas tiroideas en pacientes de hemodiálisis: Un estudio piloto". Nutricion Hospitalaria, v. 32, n. 4, p. 1808-1812, 2015.

STOCKLER-PINTO, M.B., MALM, O.; MORAES, C.; FARAGE, N.E.; SILVA, W.S.S.; COZZOLINO, M.F.; MAFRA, D. "A Follow-up Study of the Chronic Kidney Disease Patients Treated with Brazil Nut: Focus on Inflammation and Oxidative Stress". Biological Trace Element Research, v. 163, n. 1-2. p. 67-72, 2015.

STOCKLER-PINTO, M.B. et al. Effect of Brazil nut supplementation on the blood levels of selenium and glutathione peroxidase in hemodialysis patients. Nutrition, v. 26, n. 11-12, p. 1065-1069, 2010. 
SHEPARD, G.H.; RAMIREZ, H. "“Made in Brazil': Human Dispersal of the Brazil Nut (Bertholletia excelsa, Lecythidaceae) in Ancient Amazonia”. Economic Botany, v. 65, n. 1, p.44-65, 2011.

SCHOMBURG L.; KÖHRLE J. On the importance of selenium and iodine metabolism for thyroid hormone biosynthesis and human health. Mol Nutr Food Res, v. 5, p. 1235-1246, 2008.

SCOLES, R. Do rio Madeira ao rio Trombetas: novas evidências ecológicas e históricas da origem antrópica dos castanhais amazônicos. Novos Cadernos NAEA, v. 14, n. 2, p. 265-282, 2011.

THOMSON, C.D. et al. Brazil nuts: An effective way to improve selenium status. American Journal of Clinical Nutrition, v. 87, n. 2, p. 379-384, 2008.

YANG, R.; YUAN, B.C.; MA, Y.S.; ZHOU, S.; LIU, Y. The anti-inflammatory activity of licorice, a widely used Chinese herb. Pharm Biol, v. 55, p. 5-18, 2017.

YOULE, R.J.; HUANG, A.H.C. Occurence of low molecular weight and high cysteine containing albumin storage proteins in oilseeds of diverse species, American Journal of Botany, v. 68, p. 44-48, 1981

\section{Recebido em: 08/03/2022}

Aprovado em: 05/03/2022

Publicado em: 03/02/2022 